\title{
SALES PREDICTION WITH MULTIAGENT TOWN MODELS AND DECIDING STORE LOCATIONS WITH AHP
}

\author{
Kazuhiro Kohara \\ Department of Electrical, Electronics and Computer Engineering \\ Chiba Institute of Technology \\ Narashino, Chiba, Japan \\ E-mail: kohara.kazuhiro@it-chiba.ac.jp \\ Daiki Sekigawa \\ Department of Electrical, Electronics and Computer Engineering \\ Chiba Institute of Technology \\ Narashino, Chiba, Japan \\ E-mail: sekigawa.daiki@it-chiba.ac.jp
}

\begin{abstract}
We propose an integration method that uses the analytic hierarchy process (AHP) and agent-based modeling to predict sales and to choose a new store location. First, we create multiagent town models that include store agents and consumer agents. We then estimate the predicted sales for each store by using a computer simulation based on multiagent town models. Finally, we use AHP to determine the location of a new store.
\end{abstract}

Keywords: agent-based modeling, sales prediction, location decision making.

\section{Introduction}

Multiagent-based social simulations have been extensively investigated, and various attempts have been made to apply them to the layout design of supermarkets [1] and stock markets [2]. We investigated the real-world problem of predicting the sales for stores and using that prediction to determine where to locate a new store. In a conventional strategy, the predicted sales and the choice of a new store location usually depends on the skills of particular individuals. Multiple regression models are usually used as a scientific way to predict sales. However, in order to use these models, we need sales information of many stores, including those of competitors. In practice, it can be difficult to find out the sales information of competitors. Thus, we attempted to obtain sales information by using multiagent town models. Multiagent models do not require sales information of other stores. We propose an integrated method that uses the analytic hierarchy process (AHP) and agent-based modeling to predict sales and determine the location of a new store. First, we created multiagent town models that consist of store agents, consumer agents, and traffic generators. Then, we estimated the predicted sales at each store by using a computer simulation with multiagent town models. Finally, we used AHP to decide where to locate a new store. The main features of our town model are as follows: (1) realistic shape for the town, including roads; (2) two kinds of consumers: station users and town residents; (3) three kinds of traffic generators: stations, large-scale commercial facilities (large stores), and parking lots for bicycles; (4) consumer behavior 
IJAHP Article: Mu, Saaty/A Style Guide for Paper Proposals To Be Submitted to the International Symposium of the Analytic Hierarchy Process 2014, Washington D.C., U.S.A.

for busy times, based on questionnaire results; and (5) varying number of cash registers and prices.

\section{Multiagent Town Models}

We created a multiagent town model (Figure 1) based on a real town in Chiba Prefecture. The size of the target area is $1 \mathrm{~km}$ by $1 \mathrm{~km}$ because we assume consumers to travel by foot. Since the size of the town model is 200 cells by 200 cells, one cell corresponds to 5 $\mathrm{m}$ in each direction. Consumers move $80 \mathrm{~m}$ per minute, so a minute corresponds to 16 steps. In Figure 1, there are seven convenience stores. Yellow circles are traffic generators: station M, large store, and parking lots for bicycles. Green circles are possible alternative locations for a new convenience store.

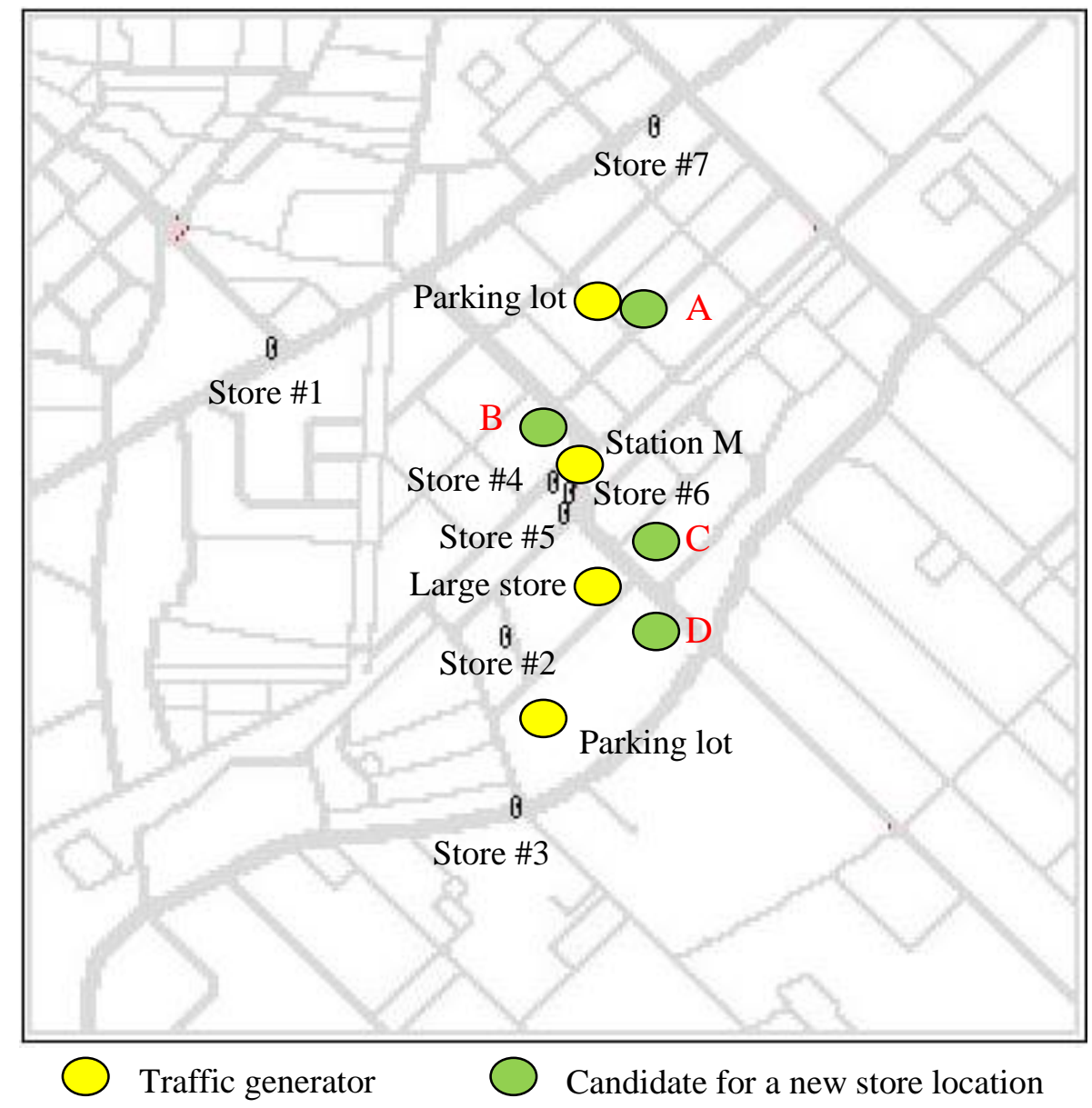

Figure 1: Multiagent town model

There are two kinds of consumer agents: station users and town residents. Station users are generated from station $\mathrm{M}$, based on the number of incoming passengers: 16,000 people per day. Based on questionnaire results, we assumed that $30.6 \%$ of the passengers visit a convenience store. The frequency with which consumers are generated depends on the number of trains per hour. The population of the target area is 22,400. We assumed 
that $16.5 \%$ of residents go to convenience stores, based on questionnaire results. Generation frequency of consumers is based on another questionnaire results. Consumer agents go to the store that has the maximum utility value, as calculated by the following equation:

Utility value $=$ Preference $-\mathrm{a} *$ (Distance between the consumer agent and a store)

$-\mathrm{b} *$ Price $-\mathrm{c} *$ (Sum of distance between a store and each traffic generator)

Preference is adjusted in order to correspond to the average sales volume at the most, the second-most and the least popular convenience stores in Japan. Each consumer agent spends 609 yen at the most popular store, 586 yen at the second-most popular store, and 522 yen at the least-popular store, according to survey results.

\section{Sales Prediction with Multiagent Town Models}

We examined the sales predictions for the seven existing stores, which averaged 554,000 yen. This is comparable to real sales data (about 500,000 yen per day) for convenience stores in Chiba Prefecture. Average sales $(675,000$ yen for the most popular stores, 577,000 yen for the second-most popular stores, and 393,000 yen for the least-popular stores) were also comparable to actual data $(682,000$ yen, 558,000 yen, and 344,000 yen, respectively). Our town models are thus comparable to real town data. By walking around the town, we selected four candidate locations (A, B, C and D) for a new store of another second-most popular convenience store which does not exist in the target area. We added one of four candidate locations to the town models and evaluated the predicted sales for each of the four new store candidates. The simulation results were as follows: 582,000 yen for A, 602,000 yen for B, 608,000 yen for C, and 550,000 yen for D.

\section{Determining a New Store Location by Using AHP}

Figure 2 shows the relative measurement AHP model created for the task of deciding on the location for the new store. Here, we used the following seven criteria: predicted sales, land price, location characteristics, visibility, building structure, time required to get to the store, and approach. All of these criteria except predicted sales are difficult to consider in a multi-agent town model. The pairwise comparison matrices for the seven criteria in three cases are shown in Tables 1 to 3. Pairwise comparisons of the alternatives with respect to the seven criteria are shown in Tables 4 to 10. Our final results are as follows: $\mathrm{A}$ is best (0.292) when sales and land price are most important, $\mathrm{C}$ is best $(0.286)$ when sales volume is most important, and $\mathrm{A}$ is best $(0.332)$ when land price is most important.

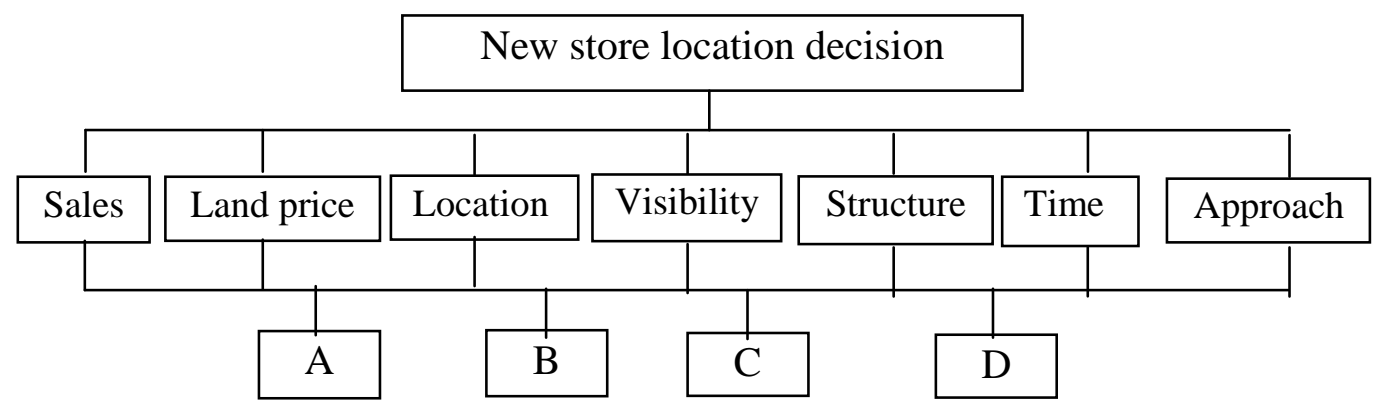

Figure 2: AHP model for new store location decision

International Symposium of

the Analytic Hierarchy

Process
3

Washington, D. C. June 29 - July 2, 2014 
IJAHP Article: Mu, Saaty/A Style Guide for Paper Proposals To Be Submitted to the International Symposium of the Analytic Hierarchy Process 2014, Washington D.C., U.S.A.

Table 1: Pairwise comparisons of seven criteria (sales and land price are most important)

\begin{tabular}{|l|c|c|c|c|c|c|c|c|}
\hline & Sales & Land & Location & Visibility & Structure & Time & Approach & Weight \\
\hline Sales & 1 & 1 & 3 & 4 & 6 & 7 & 9 & 0.313 \\
\hline Land & 1 & 1 & 3 & 4 & 6 & 7 & 9 & 0.313 \\
\hline Location & $1 / 3$ & $1 / 3$ & 1 & 2 & 4 & 5 & 7 & 0.154 \\
\hline Visibility & $1 / 4$ & $1 / 4$ & $1 / 2$ & 1 & 3 & 4 & 6 & 0.107 \\
\hline Structure & $1 / 6$ & $1 / 6$ & $1 / 4$ & $1 / 3$ & 1 & 2 & 4 & 0.054 \\
\hline Time & $1 / 7$ & $1 / 7$ & $1 / 5$ & $1 / 4$ & $1 / 2$ & 1 & 3 & 0.038 \\
\hline Approach & $1 / 9$ & $1 / 9$ & $1 / 7$ & $1 / 6$ & $1 / 4$ & $1 / 3$ & 1 & 0.021 \\
\hline
\end{tabular}

Table 2: Pairwise comparisons of seven criteria (sales is most important)

\begin{tabular}{|l|c|c|c|c|c|c|c|c|}
\hline & Sales & Land & Location & Visibility & Structure & Time & Approach & Weight \\
\hline Sales & 1 & 3 & 4 & 5 & 7 & 8 & 9 & 0.408 \\
\hline Land & $1 / 3$ & 1 & 3 & 4 & 6 & 7 & 8 & 0.256 \\
\hline Location & $1 / 4$ & $1 / 3$ & 1 & 2 & 4 & 5 & 6 & 0.137 \\
\hline Visibility & $1 / 5$ & $1 / 4$ & $1 / 2$ & 1 & 3 & 4 & 5 & 0.095 \\
\hline Structure & $1 / 7$ & $1 / 6$ & $1 / 4$ & $1 / 3$ & 1 & 2 & 3 & 0.048 \\
\hline Time & $1 / 8$ & $1 / 7$ & $1 / 5$ & $1 / 4$ & $1 / 2$ & 1 & 2 & 0.033 \\
\hline Approach & $1 / 9$ & $1 / 8$ & $1 / 6$ & $1 / 5$ & $1 / 3$ & $1 / 2$ & 1 & 0.024 \\
\hline
\end{tabular}

Table 3: Pairwise comparisons of seven criteria (land price is most important)

\begin{tabular}{|l|c|c|c|c|c|c|c|c|}
\hline & Sales & Land & Location & Visibility & Structure & Time & Approach & Weight \\
\hline Sales & 1 & $1 / 3$ & 3 & 4 & 6 & 7 & 8 & 0.256 \\
\hline Land & 3 & 1 & 4 & 5 & 7 & 8 & 9 & 0.408 \\
\hline Location & $1 / 3$ & $1 / 4$ & 1 & 2 & 4 & 5 & 6 & 0.137 \\
\hline Visibility & $1 / 4$ & $1 / 5$ & $1 / 2$ & 1 & 3 & 4 & 5 & 0.095 \\
\hline Structure & $1 / 6$ & $1 / 7$ & $1 / 4$ & $1 / 3$ & 1 & 2 & 3 & 0.048 \\
\hline Time & $1 / 7$ & $1 / 8$ & $1 / 5$ & $1 / 4$ & $1 / 2$ & 1 & 2 & 0.033 \\
\hline Approach & $1 / 8$ & $1 / 9$ & $1 / 6$ & $1 / 5$ & $1 / 3$ & $1 / 2$ & 1 & 0.024 \\
\hline
\end{tabular}

Table 4: Pairwise comparisons of alternatives with respect to sales

\begin{tabular}{|l|c|c|c|c|c|}
\hline & Location A & Location B & Location C & Location D & Weight \\
\hline Location A & 1 & $1 / 4$ & $1 / 5$ & 5 & 0.118 \\
\hline Location B & 4 & 1 & $1 / 2$ & 9 & 0.337 \\
\hline Location C & 5 & 2 & 1 & 9 & 0.508 \\
\hline Location D & $1 / 5$ & $1 / 9$ & $1 / 9$ & 1 & 0.037 \\
\hline
\end{tabular}

Table 5: Pairwise comparisons of alternatives with respect to land price

\begin{tabular}{|l|c|c|c|c|c|}
\hline & Location A & Location B & Location C & Location D & Weight \\
\hline Location A & 1 & 3 & 9 & 5 & 0.566 \\
\hline Location B & $1 / 3$ & 1 & 7 & 3 & 0.267 \\
\hline Location C & $1 / 9$ & $1 / 7$ & 1 & $1 / 5$ & 0.040 \\
\hline Location D & $1 / 5$ & $1 / 3$ & 5 & 1 & 0.127 \\
\hline
\end{tabular}

Table 6: Pairwise comparisons of alternatives with respect to location characteristics

\begin{tabular}{|c|c|c|c|c|c|}
\hline & Location A & Location B & Location C & Location D & Weight \\
\hline Location A & 1 & 5 & 2 & $1 / 3$ & 0.243 \\
\hline Location B & $1 / 5$ & 1 & $1 / 4$ & $1 / 7$ & 0.053 \\
\hline
\end{tabular}

International Symposium of $4 \quad$ Washington, D. C. the Analytic Hierarchy June 29 - July 2, 2014

Process 
IJAHP Article: Mu, Saaty/A Style Guide for Paper Proposals To Be Submitted to the International Symposium of the Analytic Hierarchy Process 2014, Washington D.C., U.S.A.

\begin{tabular}{|c|c|c|c|c|c|}
\hline Location C & $1 / 2$ & 4 & 1 & $1 / 4$ & 0.152 \\
\hline Location D & 3 & 7 & 4 & 1 & 0.551 \\
\hline
\end{tabular}

Table 7: Pairwise comparisons of alternatives with respect to visibility

\begin{tabular}{|l|c|c|c|c|c|}
\hline & Location A & Location B & Location C & Location D & Weight \\
\hline Location A & 1 & $1 / 3$ & $1 / 3$ & $1 / 4$ & 0.089 \\
\hline Location B & 3 & 1 & 1 & $1 / 2$ & 0.239 \\
\hline Location C & 3 & 1 & 1 & $1 / 2$ & 0.239 \\
\hline Location D & 4 & 2 & 2 & 1 & 0.434 \\
\hline
\end{tabular}

Table 8: Pairwise comparisons of alternatives with respect to building structure

\begin{tabular}{|l|c|c|c|c|c|}
\hline & Location A & Location B & Location C & Location D & Weight \\
\hline Location A & 1 & $1 / 2$ & $1 / 3$ & $1 / 3$ & 0.109 \\
\hline Location B & 2 & 1 & $1 / 2$ & $1 / 2$ & 0.189 \\
\hline Location C & 3 & 2 & 1 & 1 & 0.351 \\
\hline Location D & 3 & 2 & 1 & 1 & 0.351 \\
\hline
\end{tabular}

Table 9: Pairwise comparisons of alternatives with respect to time

\begin{tabular}{|c|c|c|c|c|c|}
\hline & Location A & Location B & Location C & Location D & Weight \\
\hline Location A & 1 & 2 & 3 & 4 & 0.467 \\
\hline Location B & $1 / 2$ & 1 & 2 & 3 & 0.277 \\
\hline Location C & $1 / 3$ & $1 / 2$ & 1 & 2 & 0.160 \\
\hline Location D & $1 / 4$ & $1 / 3$ & $1 / 2$ & 1 & 0.095 \\
\hline
\end{tabular}

Table 10: Pairwise comparisons of alternatives with respect to approach

\begin{tabular}{|c|c|c|c|c|c|}
\hline & Location A & Location B & Location C & Location D & Weight \\
\hline Location A & 1 & 2 & 3 & 1 & 0.351 \\
\hline Location B & $1 / 2$ & 1 & 2 & $1 / 2$ & 0.189 \\
\hline Location C & $1 / 3$ & $1 / 2$ & 1 & $1 / 3$ & 0.109 \\
\hline Location D & 1 & 2 & 3 & 1 & 0.351 \\
\hline
\end{tabular}

\section{Conclusion}

We propose integrating the AHP with agent-based modeling for predicting sales and making decisions about where to locate a new store. First, we created multiagent town models. Second, we estimated the sales of the existing convenience stores and the candidates for a new store. Third, we applied the AHP with seven criteria, including six criteria that are difficult to consider in a multiagent town model. We applied our method to an actual town and showed its effectiveness.

\section{References}

[1] Yamane, S., et al. (2012). Agent-based social simulation for a checkout layout design of a specific supermarket. MABS'12 (13th International Workshop on Multi-Agent Based Simulation).

[2] Panayi, E., et al. (2012). Agent-based modeling of stock markets using existing order book data. MABS'12. 